\title{
CONCEPÇÕES E PERCEPÇÕES DE ESTUDANTES QUANTO A CONFIABILIDADE DE NOTÍ́CIAS E FAKE NEWS
}

\section{ARTIGO ORIGINAL}

SANTOS, Ygor Bernardes ${ }^{1}$

SILVA, Ian Baruc Costa $\mathrm{e}^{2}$

GONÇALVES, Eduardo Pontello Hass ${ }^{3}$

SANTOS, Ygor Bernardes. SILVA, Ian Baruc Costa e. GONÇALVES, Eduardo Pontello Hass. Concepções e Percepções de estudantes quanto a confiabilidade de notícias e Fake News. Revista Científica Multidisciplinar Núcleo do Conhecimento. Ano 05, Ed. 09, Vol. 07, pp. 120-140. Setembro de 2020. ISSN: 2448-0959, Link de acesso: https://www.nucleodoconhecimento.com.br/educacao/confiabilidade-de-

noticias

\section{RESUMO}

Este trabalho foi feito com o intuito de analisar as concepções de Ciência, Tecnologia e Sociedade que os estudantes de uma escola estadual de Belo Horizonte evocam ao analisar a confiabilidade de notícias. Para isso, utilizamos uma sequência de ensino elaborada por estudantes do Pibid Física da UFMG baseada em um currículo CTS, que teve sua culminância em um júri simulado. A sequência foi feita a partir da seguinte questão sócio científica: "uma empresa de telefonia pretende instalar uma antena nas proximidades da escola". A partir disso, os estudantes, guiados tanto pelo professor de Física quanto pelos estudantes do Pibid, investigaram os conceitos de

\footnotetext{
${ }^{1}$ Especialista em mídias na Educação, Físico Licenciado.

${ }^{2}$ Licenciando em Física.

${ }^{3}$ Licenciando em Física.
} 
radiação e seus efeitos no ambiente. Analisamos as respostas dadas a uma das atividades feitas durante essa investigação.

Palavras-chave: CTS, fake News, ensino de física, questões sócio científicas, radiação.

\section{INTRODUÇÃO}

Boatos são um fenômeno muito antigo. Todavia, recentemente, com o surgimento da internet, eles ganharam novamente a atenção de pesquisadores como Müller e Souza (2018). Quando o processo de comunicação se dava apenas pela linguagem falada, a oralidade permitia modificações que se propagavam de diferentes formas em diversos tempos e contextos. Observamos que a comunicação humana tem um problema que parece ser inerente à ela, que é a dificuldade de assegurar a confiabilidade das informações transmitidas. Nos dias atuais, com o advento da internet, o acesso à informação ficou mais dinâmico, assim como as questões que implicam na veracidade das informações transmitidas. De acordo com Antunes, Sanches, e Lopes (2019) alguns problemas com as mentiras na internet evidenciam e tornam a navegação na rede, uma grande tarefa, pois é possível encontrar uma enorme quantidade de falsas verdades, desinformação e informação enganosa, em seu artigo, os autores discutem sobre as intervenções educativas que tentam alterar essa realidade, tentando de certa forma, formar usuários conscientes da informação.

A relevância das falácias nos dias atuais podem ser observadas pelas discussões sobre "Fake News" que ganharam força após o Brexit ${ }^{[4]}$ e as eleições de 2016 nos EUA. Muitos trabalhos científicos se propuseram a compreender e analisar o fenômeno (GELFERT, 2018), o contexto em que as fake news acontecem (MARSHALL, 2017), seus impactos (ALLCOTT e GENTZKOW, 2017), além de sua relevância (JANKOWSKI, 2018).

No Brasil, o termo Fake News tornou-se mais popular durante as eleições presidenciais de 2018. A relevância do tema e da discussão aqui se observa por meio de alguns esforços por parte do Estado brasileiro para lidar com a situação. Exemplos 
desses esforços são a instalação de uma Comissão Parlamentar Mista de Inquérito (CPMI); o incentivo e divulgação de trabalhos acadêmicos como "Post-truth, fake news e processo eleitoral." (MERGULHÃO; MERGULHÃO JUNIOR; ALBUQUERQUE, 2018) pela revista do Tribunal Regional Eleitoral de Pernambuco e pelo site do Tribunal Superior Eleitoral (TSE).

Outras evidências teóricas apontam para questões que dão relevância às fake news para nós professores e pesquisadores da educação. Müller e Souza (2018) trazem em seu referencial autores que discutem sobre as notícias falsas, como Chen; Conroy e Rubin (2015) que observam que a habilidade de julgar criticamente e avaliar a qualidade da informação é uma habilidade fundamental, mas que está carecendo em um grande segmento da população. Ou também El Rayess et al. (2018), concluem ao fazer uma pesquisa com discentes na Universidade Notre Dame-Louaize (NDU), no Líbano, que os estudantes, não costumam avaliar e verificar a veracidade de informações e observam que ao não dar atenção sobre a veracidade das informações eles podem se tornar alvos fáceis das Fake News, associando o fato excesso de autoconfiança em suas habilidades de avaliação.

De forma mais objetiva Müller e Souza (2018), falam sobre a importância da atuação docente, segundo eles os jovens devem necessitar de mais apoio para estender capacidades para fazer um julgamento crítico das fontes de informação. Sendo assim, segundo os autores, a alfabetização informacional deve auxiliar os jovens a aumentar as habilidades para julgar as informações e suas fontes.

Estas referências citadas anteriormente incumbem a nós educadores o papel de sermos também responsáveis pelo enfrentamento, direto e indireto, às "Fake News". Tendo isso em vista, uma questão levantada foi: $O$ ensino de ciências pode auxiliar no enfrentamento de atribulações como das "Fake News"?

Sendo a Pós-Verdade um fenômeno que não toca somente em âmbitos políticos eleitorais e sim em todos os contextos sociais que estamos imersos, é natural ver que, também na ciência, as "Informações Falsas" se farão presentes. Sendo assim, como responsáveis pela difusão do conhecimento científico, através de propostas 
pedagógicas, buscamos encontrar caminhos para avaliar as Fake News relacionadas à ciência e possíveis ferramentas para combatê-las. Apresentamos este trabalho como uma proposta para responder às seguintes perguntas de pesquisa: Quais concepções de ciência, tecnologia e sociedade os estudantes evocam em suas construções de argumentos ao analisar notícias? De que forma esses argumentos evocados pelos estudantes são capazes de combater ou minimizar os impactos das notícias falsas na sociedade?

Pretendemos responder a essas perguntas analisando uma sequência de ensino elaborada por estudantes do Programa Institucional de Bolsas de Iniciação à Docência (PIBID) da Universidade Federal de Minas Gerais (UFMG), que foi aplicada em estudantes de duas turmas do terceiro ano do ensino médio de uma escola estadual de Belo Horizonte, na região da Pampulha, no turno noturno. Baseamos a sequência em uma abordagem Ciência, Tecnologia e Sociedade (CTS) que, segundo Santos e Mortimer (2002) citando López e Cerezo (1996), corresponde a uma integração entre educação científica, tecnológica e social, onde os conteúdos científicos e tecnológicos permeiam uma discussão entre os aspectos históricos, éticos, socioeconômicos e políticos.

A sequência foi feita com os professores de Física e Biologia, juntamente com cinco estudantes do Pibid, durante um bimestre do ano de 2019. Sua culminância foi um júri simulado feito com as duas turmas, cada uma com quarenta discentes, onde foram discutidas as consequências da instalação de uma antena de telefonia nas proximidades da escola.

Essa sequência constituiu-se de dez aulas apresentadas resumidamente na tabela 1, que pode ser vista a seguir. A primeira coluna da tabela apresenta o número da aula. A segunda coluna descreve de maneira sucinta as atividades realizadas nas respectivas aulas e a terceira coluna é composta pelo levantamento das dimensões de Ciência, Tecnologia e Sociedade em que se pautaram as aulas, baseadas nos referenciais teóricos adotados. Por praticidade, agrupamos a sexta e sétima aula pois elas foram constituídas de uma mesma atividade, que necessitou de mais tempo. 
Tabela 1: Resumo das aulas.

\begin{tabular}{|c|c|c|}
\hline Aula & Síntese das atividades & $\begin{array}{l}\text { Aspecto CTS } \\
\text { predominante }\end{array}$ \\
\hline 1 & $\begin{array}{l}\text { Apresentação de vídeos encontrados na internet, } \\
\text { envolvendo radiação, discussão com os estudantes } \\
\text { sobre os seus conceitos prévios de radiação. } \\
\text { Levantamento de dúvidas sobre radiação. } \\
\text { Sistematização de conceitos sobre ondas } \\
\text { eletromagnéticas. }\end{array}$ & $\begin{array}{l}\text { Científico e } \\
\text { tecnológico. }\end{array}$ \\
\hline 2 & $\begin{array}{l}\text { Divisão da turma em dois grupos. Um grupo foi à sala } \\
\text { de informática pesquisar sobre as dúvidas apresentadas } \\
\text { na aula anterior, o outro grupo discutiu em sala, } \\
\text { utilizando o senso comum e os conceitos discutidos } \\
\text { anteriormente. }\end{array}$ & $\begin{array}{l}\text { Científico } \\
\text { social. }\end{array}$ \\
\hline 3 & $\begin{array}{l}\text { Distribuição de uma atividade desenvolvida pelo Centro } \\
\text { de Ensino de Ciências e Matemática de Minas Gerais } \\
\text { (Cecimig), que discutia os impactos da radiação na } \\
\text { saúde, apresentando diversos trechos de pessoas que } \\
\text { falavam sobre como a radiação afetou sua vida, assim } \\
\text { como resultados de pesquisas científicas. Discussão } \\
\text { sobre a confiabilidade de notícias em variados meios de } \\
\text { comunicação. }\end{array}$ & $\begin{array}{l}\text { Científico, } \\
\text { tecnológico e } \\
\text { social. }\end{array}$ \\
\hline 4 & $\begin{array}{l}\text { Discussão sobre a atividade da terceira aula, com } \\
\text { socialização das respostas dadas pelos estudantes. }\end{array}$ & $\begin{array}{l}\text { Científico, } \\
\text { tecnológico e } \\
\text { social. }\end{array}$ \\
\hline 5 & $\begin{array}{l}\text { Divisão dos grupos, sendo um a favor da instalação de } \\
\text { uma antena de telefonia celular nas imediações da } \\
\text { escola e outro contra a instalação, para o júri simulado. } \\
\text { Explicação do tema e do funcionamento de um júri. }\end{array}$ & $\begin{array}{l}\text { Científico } \\
\text { social. }\end{array}$ \\
\hline
\end{tabular}


6 e 7 Preparação dos grupos para o júri, com cada grupo em Científico, uma sala separada, procurando um menor número de tecnológico e interferência nos discursos entre os grupos. social.

8 Apresentação do júri simulado. Científico, tecnológico e social.

9 e Discussão sobre os resultados e sobre os processos Científico, 10 argumentativos que aconteceram durante o júri. tecnológico e social.

Fonte: autor.

\section{DESENVOLVIMENTO}

Para fazermos as análises, usaremos três concepções de ciência, três de tecnologia e três de sociedade e iremos categorizar as respostas à atividade de acordo com as concepções usadas na construção dos argumentos pelos estudantes. Pretendemos, assim, avaliar que tipo de concepções de ciência, tecnologia e sociedade estão sendo ensinadas nas aulas de Física e, se possível, fazer paralelos com as fake news e suas implicações junto à sociedade.

\section{CIÊNCIA}

Inicialmente, traremos a concepção mais rotineira de ciência por Palacios et al. (2005), que diz que "de acordo com a concepção tradicional ou 'concepção herdada' da ciência, esta é vista como um empreendimento autônomo, objetivo, neutro e baseado na aplicação de um código de racionalidade distante de qualquer tipo de interferência externa". (PALACIOS et al., 2005, p. 14)

Outra concepção de ciência que usaremos é também definida por Palacios et al. (2005), em que

um argumento que contrapõe esta noção de ciência, que se apoia num método de caráter indutivo, vem sustentado pela própria história da 
ciência. Em princípio, a história mostra que numerosas ideias científicas surgem por múltiplas causas, algumas delas vinculadas à inspiração, à sorte em contextos internos das teorias, aos condicionamentos socioeconômicos de uma sociedade, sem que seja seguido, em todos os casos, um procedimento padrão ou regulamentado. (PALACIOS et al., 2005, p. 15)

Nossa terceira concepção de ciência é trazida de Fonseca (2007), que fala que

o papel da ciência na atualidade não é mais entendido como a busca de domínio do mundo, mas sim salvaguardá-lo, em um contexto em que o conhecimento científico ainda representa uma forma de poder que é entendido como uma prática social, econômica e política e um fenômeno cultural mais do que um sistema teórico-cognitivo. A ciência está no cotidiano e vem merecendo, cada vez mais, um atento olhar das ciências sociais no sentido de extrair a compreensão de sua extensão e de seu lugar na sociedade e na história. (FONSECA, 2007, p.36)

A fim de simplificar os trabalhos póstumos de leitura e análise das respostas sintetizamos as concepções acima como: 1 - Ciência pautada em um modelo tradicional, universal, neutra e imparcial; 2 - Ciência majoritariamente tradicional, com a inclusão de uma perspectiva histórica; 3 - Ciência vista como uma prática social, economia e política, incluída em diversos aspectos das relações humanas.

\section{TECNOLOGIA}

Com relação às concepções de tecnologia, iniciamos com Santos e Mortimer (2002), que definem que a tecnologia pode ser decifrada como o conhecimento que permite o indivíduo controlar e transformar o mundo.

Usaremos também a definição de Palacios et al. (2005), em que:

a tecnologia poderia ser considerada como o conjunto de procedimentos que permitem a aplicação dos conhecimentos próprios das ciências naturais na produção industrial, ficando a técnica limitada aos tempos anteriores ao uso dos conhecimentos científicos como base do desenvolvimento tecnológico industrial. (PALACIOS et al., 2005, p. 39)

Nossa última definição será também de Palacios et al. (2005) 
Centrando-nos agora na relação ciência-tecnologia, muitos autores têm demonstrado que esta é o critério que diferencia a técnica da tecnologia [..]. O termo "técnica" faria referência a procedimentos, habilidades, artefatos, desenvolvimentos sem ajuda do conhecimento científico. $O$ termo "tecnologia" seria utilizado, então, para referir-se àqueles sistemas desenvolvidos levando em conta esse conhecimento científico. (PALACIOS et al., 2005, p. 37)

Assim como foi feito com as concepções do eixo Ciências, as concepções de Tecnologia escolhidas podem ser resumidas como: 1 - Tecnologia como forma de modificar o mundo e controlar o mundo; 2 - Tecnologia como busca do progresso industrial e social; 3 - Tecnologia como ciência aplicada.

\section{SOCIEDADE}

Para definir sociedade, pautamo-nos inicialmente no pressuposto teórico trazido por Palacios et al. (2005), pautada nos pressupostos de Luhmann, que "considera a sociedade como mais um entre diferentes tipos de sistemas. Os sistemas podem ser máquinas, organismos, sistemas psíquicos e sistemas sociais" (p.81)

Uma segunda definição de sociedade é proposta também por Palacios et al. (2005), que dizem que existe nos humanos uma tendência à sociabilidade e que as estruturas sociais se formam desde às mais até às menos estáveis e complexas, compondo-se por uma estrutura natural, que possibilita a caracterização de uma espécie. Contudo, segundo os autores, essa caracterização não é exclusiva dos humanos.

Outra concepção de sociedade é trazida por Simon, citado por Santos e Mortimer (2002) no artigo Uma análise de pressupostos teóricos da abordagem C-T-S (Ciência - Tecnologia - Sociedade) no contexto da educação brasileira. Segundo eles , a sociedade pode ser vista como e um corpo orgânico que tem em sua estrutura inteiros níveis da vida social, tendo como alicerce o agrupamento de indivíduos que vivem sob determinados sistemas econômicos de produção e também sistemas de distribuição e consumo, ancorados em um regime político, que obedece a normas, leis e necessárias à manutenção da sociedade como um todo. 
Por fim resumimos as concepções de Sociedade como: 1 - Sociedade como um sistema estruturado, fechado e imutável ; 2 - Sociedade como uma estrutura natural e parcialmente mutável ; 3 - Sociedade como um organismo vivo e mutável.

As concepções que irão compor o referencial teórico deste trabalho, da forma como foram sintetizadas, estão apresentadas em três eixos na tabela 2 a seguir, a fim de facilitar a leitura e nosso processo de análise das respostas. Posteriormente apresentar-se-á a justificativa que proporcionou tal escolha e uma correlação entre ciência, tecnologia e sociedade a fim de formar a abordagem CTS.

Tabela 2- Sínteses das concepções de Ciências, Tecnologia e Sociedade

\begin{tabular}{|c|c|c|c|}
\hline & Ciência & Tecnologia & Sociedade \\
\hline $\begin{array}{l}\text { Concepção } \\
1\end{array}$ & $\begin{array}{l}\text { Ciência pautada em } \\
\text { um modelo tradicional, } \\
\text { universal, neutra e } \\
\text { imparcial }\end{array}$ & $\begin{array}{lr}\text { Tecnologia } & \text { como } \\
\text { forma } & \text { de } \\
\text { modificar } & o \\
\text { mundo } & \text { e } \\
\text { controlar } & o \\
\text { mundo } & \end{array}$ & $\begin{array}{l}\text { Sociedade como } \\
\text { um sistema } \\
\text { estruturado, } \\
\text { fechado } \\
\text { imutável }\end{array}$ \\
\hline $\begin{array}{l}\text { Concepção } \\
2\end{array}$ & $\begin{array}{l}\text { Ciência } \\
\text { majoritariamente } \\
\text { tradicional, com a } \\
\text { inclusão de uma } \\
\text { perspectiva histórica }\end{array}$ & $\begin{array}{l}\text { Tecnologia como } \\
\text { busca do } \\
\text { progresso } \\
\text { industrial e social }\end{array}$ & $\begin{array}{l}\text { Sociedade como } \\
\text { uma estrutura } \\
\text { natural } \quad \text { e } \\
\text { parcialmente } \\
\text { mutável }\end{array}$ \\
\hline $\begin{array}{l}\text { Concepção } \\
3\end{array}$ & $\begin{array}{l}\text { Ciência vista como } \\
\text { uma prática social, } \\
\text { economia e política, } \\
\text { incluída em diversos } \\
\text { aspectos das relações } \\
\text { humanas }\end{array}$ & $\begin{array}{l}\text { Tecnologia como } \\
\text { ciência aplicada }\end{array}$ & $\begin{array}{l}\text { Sociedade como } \\
\text { um organismo } \\
\text { vivo e mutável }\end{array}$ \\
\hline
\end{tabular}

Fonte: autor. 


\section{CIÊNCIA, TECNOLOGIA E SOCIEDADE}

A escolha da ordem em que as definições de Ciência, Tecnologia e Sociedade foram colocadas se deu devido a suas similitudes. Encontramos conexões lógicas entre as concepções, visto que algumas apresentavam visões de mundo semelhantes e, portanto, classificamo-nos com a mesma numeração. Sendo assim, espera-se que uma resposta classificada como concepção um de Ciência seja classificada como concepção um tanto em Tecnologia quanto em Sociedade (o mesmo vale para as concepções dois e três). A seguir apresentaremos as conexões que entendemos entre cada uma das concepções.

As concepções enumeradas como um dizem respeito a uma visão dos aspectos segundo o ensino tradicional, onde podemos observar a Ciência como algo ideal, neutro e irrefutável. A Tecnologia aqui é tratada como uma ferramenta perfeita da própria Ciência, responsável por modificar e controlar o mundo, sendo da mesma forma imparcial e inquestionável. Já a Sociedade reproduz a idealização da Ciência e responde ao controle da Tecnologia, portando-se como um sistema bem estruturado e fechado para questões não científicas.

Na concepção dois a Ciência é tratada de forma parecida com a concepção um, porém adquire aqui uma contextualização histórica que remove parcialmente seu caráter ideal e infalível. A concepção de Tecnologia se sustenta numa proposta desenvolvimentista, em que esses artefatos e procedimentos são os resultados da construção histórica da Ciência e assim os responsáveis e os medidores de um desenvolvimento industrial e social. A Sociedade, por sua vez, a partir destas ideias de Ciência e Tecnologia, ainda se trata de uma estrutura bem organizada, porém surge naturalmente e é capaz de sofrer alterações. Já que a Ciência dita a realidade e evolui com o passar do tempo e a Tecnologia tem como fundamento o desenvolvimento, é esperado que o sistema social se desenvolva segundo os eixos anteriores.

A terceira concepção de Ciência traz uma ideia desta como uma prática construída, mutável, dependente do meio em que está inserida. Na concepção em questão, a 
Tecnologia é dada como uma extensão direta da Ciência, sendo vista como um sistema de práticas e conhecimentos que evolui com e a partir dos conceitos científicos. Já a concepção de Sociedade trata de um organismo vivo, mutável, que transforma as suas questões internas e é transformado pelas mesmas. Assim sendo, existe um elo de retroalimentação entre os três eixos, já que eles existem simultaneamente dentro um do outro e são responsáveis pelas modificações um do outro.

\section{METODOLOGIA}

Para a realização deste trabalho fizemos, inicialmente, uma pesquisa bibliográfica sobre as concepções de Ciência, Tecnologia e Sociedade que estão presentes nos artigos anexados ao Google Scholar, até o período de outubro de 2019. Fizemos também um levantamento das produções que iriam auxiliar na compreensão de diferentes pontos de vista e iriam possibilitar, posteriormente, uma análise.

Usamos as concepções mostradas na contextualização teórica para avaliar como os estudantes, em um contexto de ensino CTS, ao responderem perguntas específicas, retomam as suas próprias concepções de Ciência, Tecnologia e Sociedade. As principais perguntas que tentamos responder foram: Como os estudantes constroem essas respostas? De que forma eles retomam os conceitos de ciência, tecnologia e sociedade? Que conceitos são esses?

Para responder a essas perguntas, utilizamos as questões feitas aos estudantes presentes nas aulas três e quatro da sequência de ensino e suas respostas a essas questões; ambas se encontram na tabela 3, que pode ser encontrada a seguir. A sequência de ensino em questão era pautada em aspectos CTS e foi composta por uma questão socio científica, que envolvia uma discussão sobre os riscos de uma antena de telefonia ser instalada perto da escola, retomando a problematização inicial, das aulas, que era referente a implicação da radiação e o ser humano. A SE completa pode ser encontrada em outro trabalho dos autores. As aula três e quatro constituíramse na distribuição de uma atividade desenvolvida pelo CECIMIG, discutindo os impactos da radiação na saúde e a confiabilidade de notícias. 
Tabela 3 - Perguntas e respostas

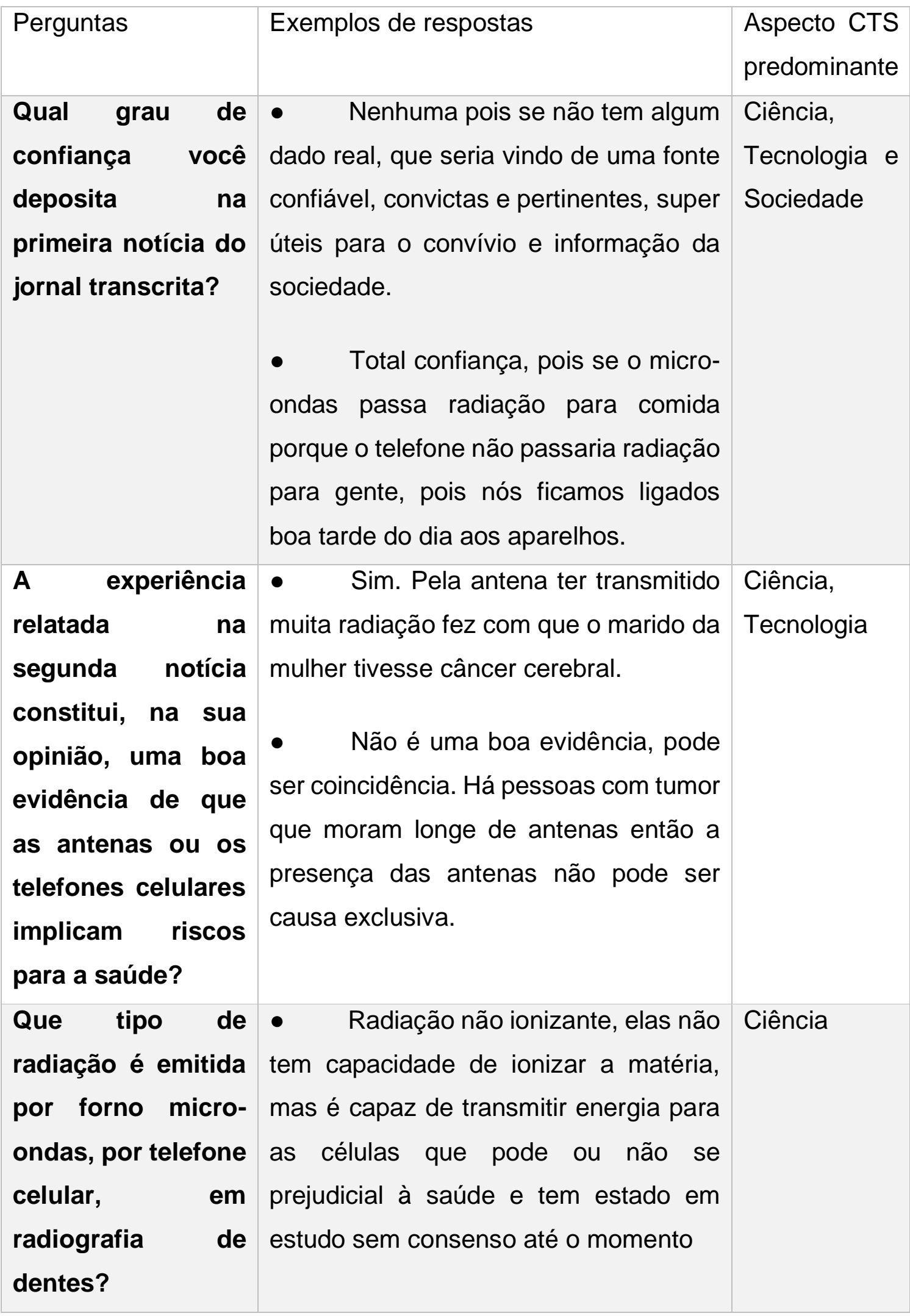




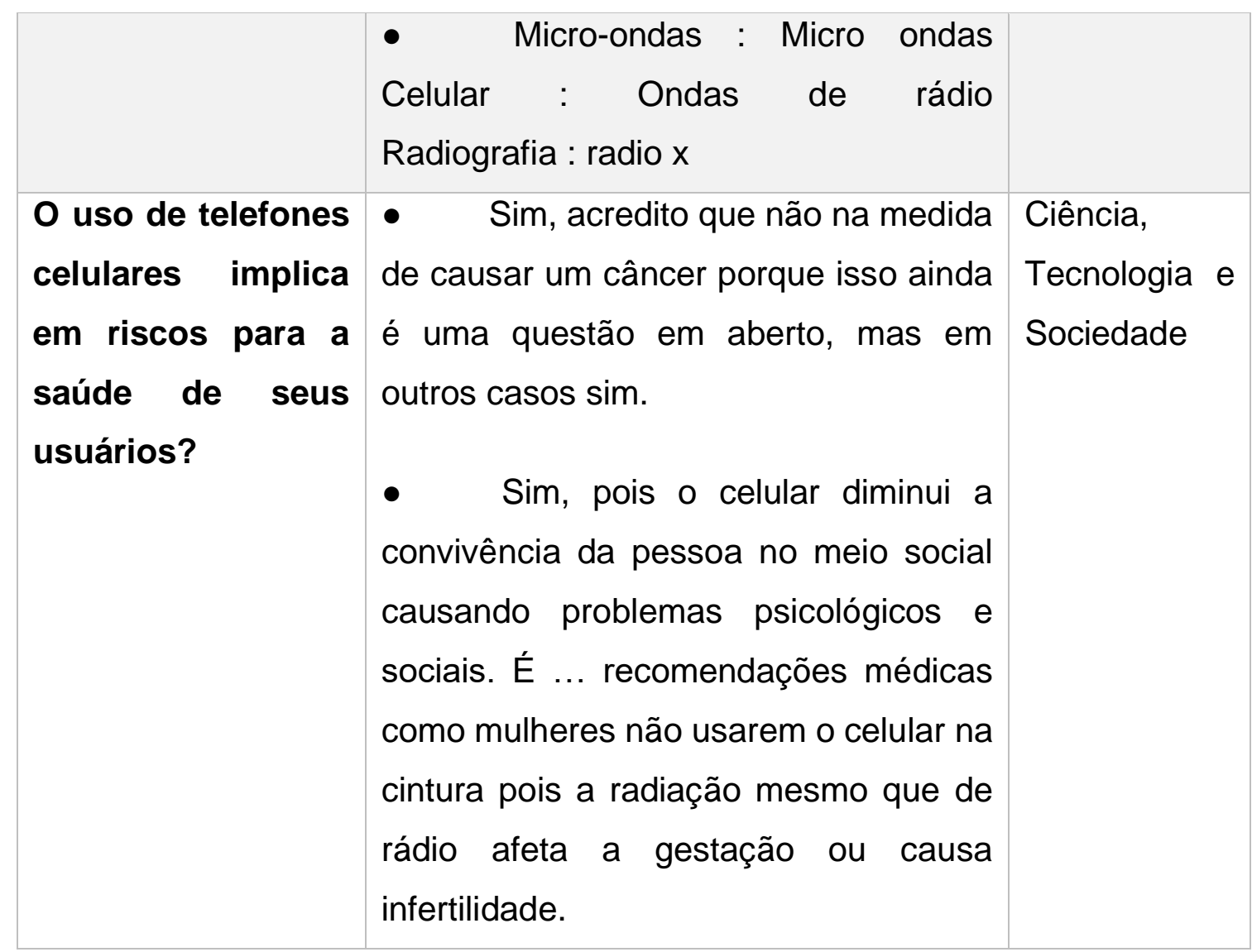

Fonte: autor.

$\mathrm{Na}$ coluna de respostas encontradas nas tabela 3, apresentada anteriormente, algumas palavras encontram-se grafadas exatamente como os alunos escreveram em suas atividades. A não alteração para a forma culta da língua se deu por entendermos que possíveis mudanças poderiam acarretar diferenças nos sentidos e significados atribuídos inicialmente pelos discentes.

Para fazer as análises das respostas dadas pelos discentes nestas aulas e atividades, tabulamos todas as perguntas em uma planilha com as respectivas respostas e fizemos a leitura de cada uma, atribuindo a cada resposta uma concepção de Ciência, uma de Tecnologia e uma de Sociedade conforme o referencial teórico, que apresentaremos brevemente na seção de resultados a seguir. 


\section{RESULTADOS}

Para compreender melhor os resultados e análises que serão apresentadas a seguir, faremos a apresentação das reportagens que os estudantes leram. Notícia 1: Uma comissão de especialistas reuniu uma grande quantidade de evidências de cientistas e, em audiências públicas, ao longo do país, concluiu que as antenas e os celulares estão arruinando vidas e prejudicando a saúde da população. Notícia 2: Uma mulher, cujo marido teve um tumor cerebral diagnosticado depois que uma antena foi colocada a 20 jardas de sua casa, recebeu bem às notícias da noite anterior. Ela declarou: Eu acredito que essas antenas são uma ameaça e um risco à saúde. Notícia 3: ... À medida que o tempo passou, a família e suas duas crianças perceberam que eles não estavam dormindo tão bem quanto costumavam, algo que, agora, eles sabem que têm ligação com radiação de micro-ondas, de acordo com uma pesquisa de laboratório. A mulher, então, notou que, se ela se machucasse, sua pele demorava, cada vez mais, para cicatrizar e sua memória recente estava piorando.

Após a leitura, os estudantes responderam às perguntas escritas na tabela 3. Um total de 13 atividades foi recolhido dos estudantes e analisado posteriormente. Alguns exemplos de respostas estão expostas na tabela 3 juntamente com a classificação das dimensões a serem avaliadas.

A partir da análise das respostas entregues pelos estudantes, elaboramos os gráficos a seguir: 
Gráfico 1 - Qual grau de confiança você deposita na primeira notícia do jornal transcrita?

8

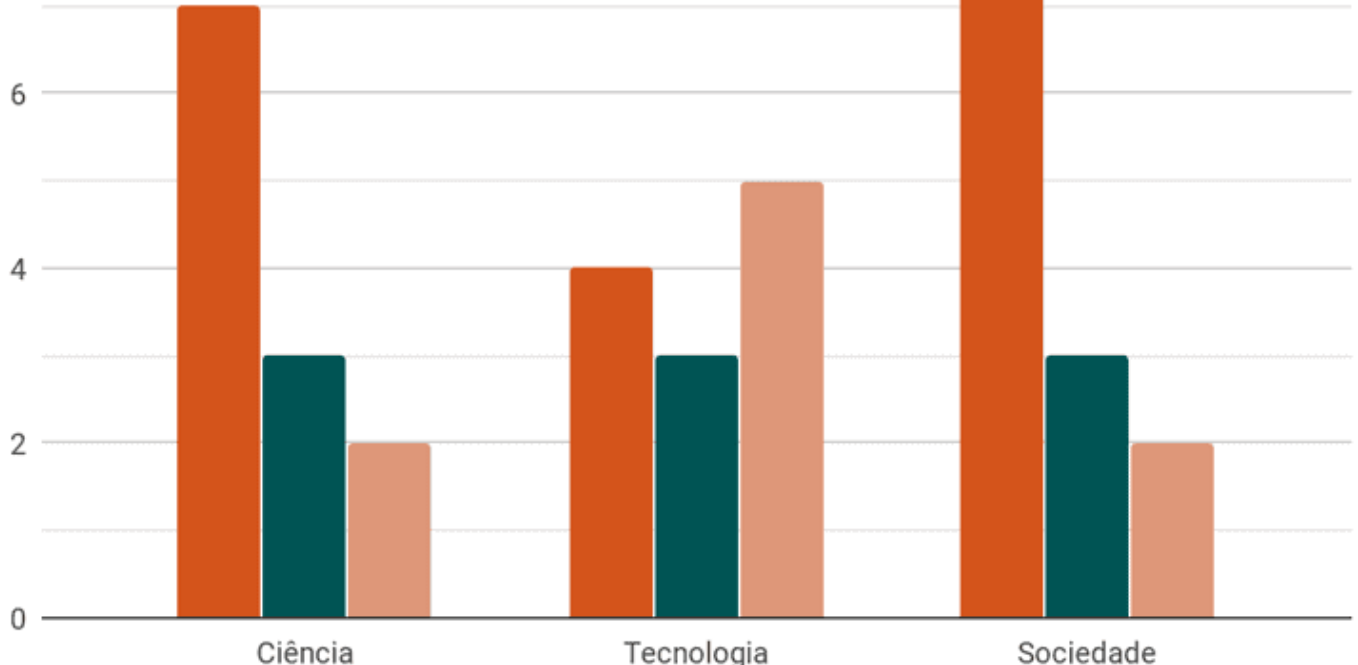

Fonte: autor.

Essa pergunta tem como principal objetivo identificar quais conceitos, concepções e conjecturas os estudantes apresentam para justificar a confiança atribuída a uma notícia de jornal. Por exemplo: um grupo de estudantes respondeu que não deposita confiança alguma na notícia e justificou isto com o fato de não ser uma fonte confiável. Com isso, observa-se que os discentes não apresentam nenhum argumento científico ou tecnológico para justificar as suas escolhas. Entretanto, um outro grupo apontou total confiança na notícia de jornal transcrita, evocando conceitos científicos tais como as micro-ondas como forma de radiação que pode ser absorvida pelos alimentos, ou o celular, que emite ondas e estas podem ser consideradas como radiação, afirmando que o celular pode, sim, causar alguma "modificação" no ser humano. De toda forma, pode-se verificar que existe uma grande discrepância nas respostas dos grupos, um atribuindo alto grau de confiança à reportagem e outro atribuindo confiança nenhuma. Consideramos a presença ou não da linguagem científica de extrema relevância, pois nosso objetivo foi identificar quais concepções estão presentes nas respostas dos 
estudantes. Assim, a ausência de concepções científicas evidentes apresentou-se como um possível problema, podendo significar que alguns estudantes não evocam argumento científicos para corroborar ou refutar uma notícia.

Foi possível observar a predominância da concepção um de ciência, visto que, os estudantes, ao responder à atividade, por vezes usaram seus conceitos científicos sem levantar hipóteses sobre os contextos das reportagens, considerando a ciência universal e inquestionável e não levantando qualquer questionamento sobre a radiação do celular poder ou não causar câncer e sobre quais poderiam ser as variáveis atribuídas a tal evento.

Notamos que os discentes, ao responderem as perguntas, incorreram nas concepções um e três de tecnologia. Atribuímos esses resultados ao fato de a concepção um de ciência estar diretamente ligada à concepção um de tecnologia, tratando os artefatos como as causas determinantes na modificação da situação, como podemos perceber nesta fala: "porque o celular causa radiação e radiação para a nossa saúde é horrível, por causa do câncer", em que o artefato tecnológico aqui é fatalmente responsável por alterar a saúde das pessoas. A concepção três de tecnologia pode ser vista em respostas como: "um grau médio de confiança, porque o celular transmite radiação não-ionizantes, sendo que o nosso corpo possui íns." se mostrando através da descaracterização do artefato tecnológico, tratando-o apenas como subproduto da ciência.

A concepção de sociedade que mais apareceu nas respostas à primeira pergunta foi a concepção um, que considera a sociedade como um sistema fechado, rígido e imutável. Um grupo deu a seguinte resposta: "nenhum grau de confiança, pois nós vivemos numa sociedade muito consumista que utiliza de notícias populares da saúde para aumentar suas vendas, como menos radiação ou nenhuma". Pode-se observar nesta resposta a ideia de sociedade como um sistema rígido, e que por sua vez também não leva em consideração as diferenças entre os grupos sociais e suas particularidades. Os estudantes trazem para essa resposta apenas as concepções de sociedades que eles mesmos pertencem, em momento algum levando em consideração a existência de outras sociedades que usam menos o celular. 
Gráfico 2 - A experiência relatada na segunda notícia constitui, na sua opinião, uma boa evidência de que as antenas ou os telefones celulares implicam riscos para a saúde?

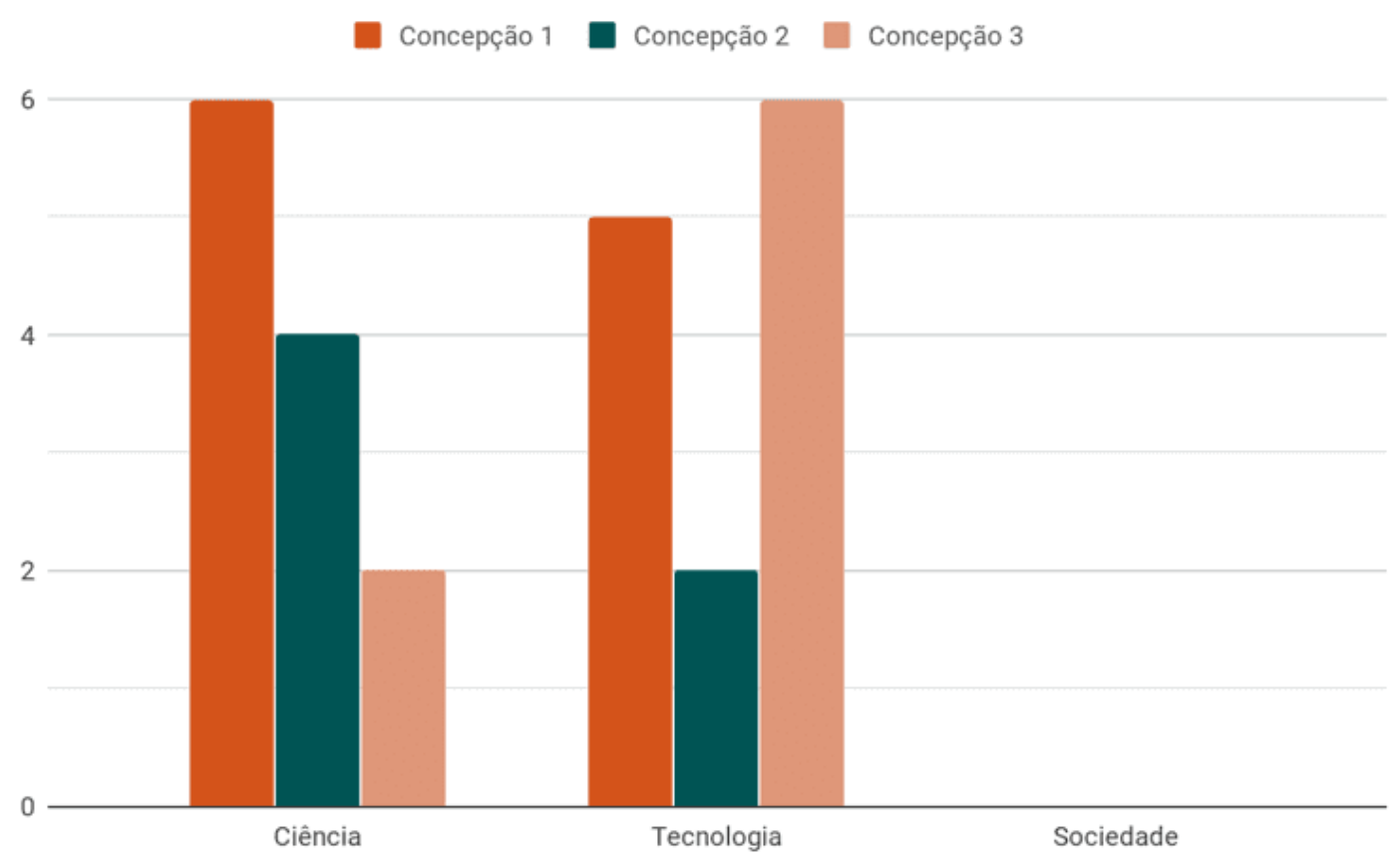

Fonte: autor.

Nesta pergunta, analisamos apenas o que tange às concepções de ciência e tecnologia, pois os estudantes pouco apresentaram aspectos sociais em suas respostas.

Novamente vemos a predominância da concepção um de ciência, explicitada nesta resposta de um grupo, que diz: "Pela antena ter transmitido muita radiação fez com que o marido da mulher tivesse câncer cerebral". Para nós, o principal indício dessa resposta pertencer à concepção um de ciência está no fato dos estudantes conectarem diretamente o evento a um conceito científico, sem levantar hipóteses sobre os contextos do evento, transmitindo novamente a ideia de que a ciência acontece de forma linear e infalível. Podemos também identificar isso quando dizem que é sabido pelos cientistas que o indivíduo, uma vez exposto a muita radiação, terá câncer. 
Observou-se também algo como um equilíbrio entre as concepções um e três de tecnologia; a maioria dos estudantes remete-se à tecnologia como uma simples forma de aplicação da ciência, não levando em consideração o seu caráter holístico ou as características sociais do fazer científico. A exemplo da resposta "A colocada da antena perto da residência não pode implicar no aparecimento de um temor, os celulares e as antenas sim emitem uma radiação cujo nome é rf (radiofrequência) a frequência é pouca e a quantidade de radiação emitida é pouca, não suficiente para causar um tumor, muito menos em alguns dias." em que podemos observar toda uma construção de argumentos baseada unicamente no caráter científico da tecnologia em questão. Entretanto, esse caráter científico está vinculado à concepção um de ciência, tornando a tecnologia determinística e idealizada.

Atribuímos o aparecimento da concepção um de tecnologia nas respostas a essa pergunta ao fato de muitos estudantes acreditarem que a tecnologia tem a função de ser algo que fornece ao indivíduo a capacidade de modificar e controlar o mundo, como podemos verificar na seguinte resposta dada por um dos grupos: " não é confiável, pois a mulher tirou essa conclusão por achar que as antenas fossem a razão da doença do marido". Analisando essa resposta, podemos observar que os discentes atribuem à antena, aqui considerado como artefato tecnológico, a possibilidade de causar ou não o câncer no marido. 
Gráfico 3 - Que tipo de radiação é emitida por forno micro-ondas, por telefone celular, em radiografia de dentes?

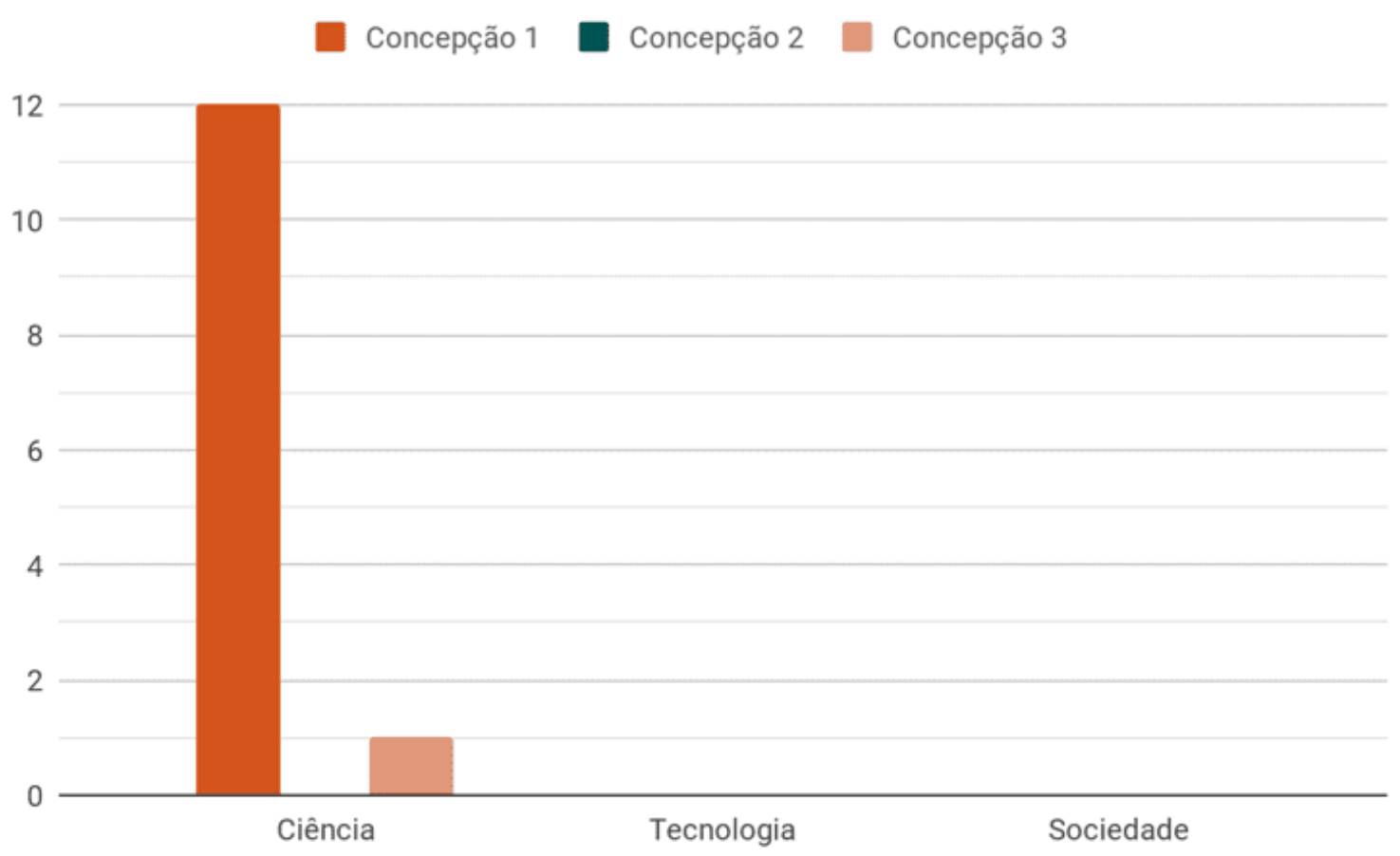

Fonte: autor.

Nesta pergunta, observamos a quase unanimidade da concepção um de ciências, a que atribuímos a forma como a pergunta foi construída; para nós, ela apresenta-se como na maioria dos livros didáticos, onde os estudantes precisam dar uma resposta correta, aqui compreendida como única e indiscutível, impossibilitando a existência de divergências entre os grupos. Uma pergunta elaborada nos moldes tradicionais tende a guiar os estudantes a respostas mais tradicionais. Muitos estudantes neste momento abriram o livro didático ou mesmo a internet para pesquisar que tipos de radiação são emitidos por diferentes fontes, a fim de encontrar respostas como radiação de micro-ondas, ondas de rádio e raios-x. Ressaltamos que tais respostas não significam que os estudantes compreenderam a diferença entre uma radiação chamada de ondas de rádio e uma radiação chamada de raio $\mathrm{x}$, mantendo, assim, a necessidade de percorrer outros caminhos para a apresentação desse conteúdo aos discentes. 
Gráfico 4 - O uso de telefones celulares implica em riscos para a saúde de seus usuários?

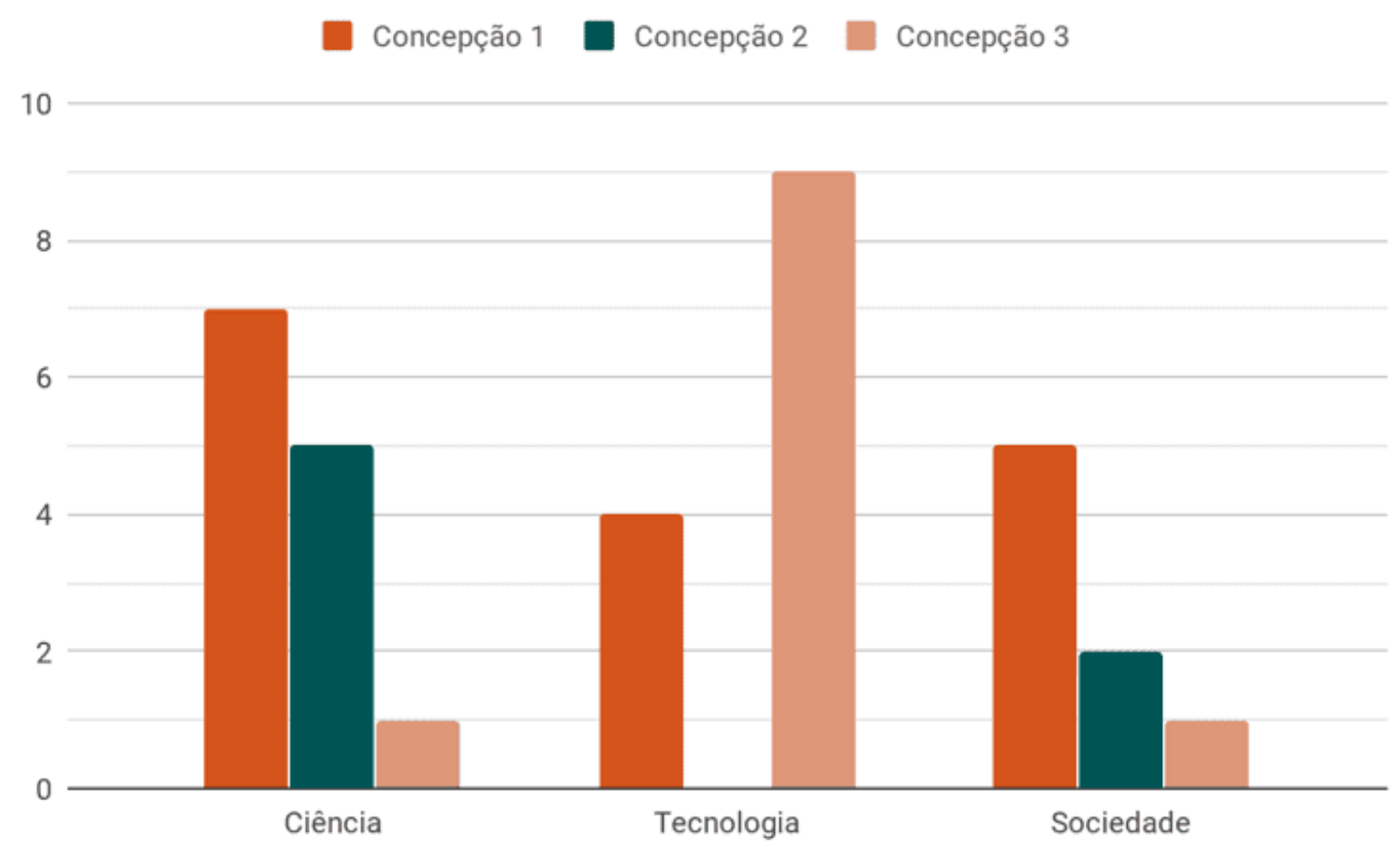

Fonte: autor.

Durante a análise dos gráficos, foi possível observar a predominância da concepção um de ciências em todos eles, com a concepção dois aparecendo em alguns como a segunda mais levantada pelos estudantes. Um exemplo de resposta atribuída a concepção um apresenta-se na seguinte resposta: "a radiação emitida não prejudicou a saúde, pois da emitida não são capazes de destruir as células de DNA". Pode-se observar que os estudantes não levantam hipóteses, apenas respondem prontamente que a radiação não é capaz de destruir as células de DNA, apresentando a ciência como uma certeza universal.

Um exemplo da concepção dois que foi observada nessa resposta pode ser lido a seguir: "Alguns testes de radiação feito com ratos mostrou o desenvolvimento de tumores nos mesmo, ainda é discutida se o celular traz riscos à saúde humana." Essa resposta nos remete a uma ideia de que as certezas de que a ciência nos traz são 
produzidas ao longo do tempo, remetendo à ideia de que existe, sim, uma perspectiva histórica na progressão dos saberes científicos.

Ao fazer a análise dos resultados, observamos um grande número de respostas que tendiam à concepção um de ciências e à concepção três de tecnologia, o que nos fez levantar indagações, pois o esperado era que, conforme mencionado anteriormente, as concepções um fossem intimamente ligadas entre si, assim como as concepções dois e três. Um exemplo de resposta nesse formato foi: "Não, os níveis de exposição à radiação e o tempo de duração colocam esse risco em um patamar muito baixo". Entendemos que, nesse caso, a Ciência é tratada como irrefutável e a Tecnologia como algo que reproduz na prática as verdades inegáveis desta mesma Ciência.

Tanto no exemplo anterior como em outros, como na resposta "Sim, pois tem radiação de ondas de rádio.", não fomos capazes de determinar qual concepção de Sociedade foi evocada para responder à pergunta proposta. É possível que tais colocações não sejam compatíveis com nenhuma das definições de sociedade apresentadas neste artigo, já que em nenhum momento o fator social foi apresentado como um ponto relevante do problema apresentado. Sendo assim, estas respostas não foram classificadas no eixo Sociedade.

Quanto à análise das concepções de Sociedade como um todo, podemos observar uma maioria de respostas tendendo à concepção um. Na resposta "Sim, pois o celular diminui a convivência da pessoa no meio social causando problemas psicológicos e sociais. É ...[5] recomendações médicas como mulheres não usarem o celular na cintura pois a radiação mesmo que de rádio afeta a gestação ou causa infertilidade.", observamos uma crença de que a sociedade funciona como um sistema rígido e estruturado. A forma como o celular foi tratado como um problema social não demonstra possibilidade de modificação, sendo um fato social imutável e inegável. Quando mais questões científicas são apresentadas, como as recomendações médicas, o fatalismo do problema social não se altera, apenas são acrescentadas medidas paliativas para questões que a Ciência vista como tradicional e inegável pode prever e controlar. 


\section{CONSIDERAÇÕES FINAIS}

Ao compreender o contexto dos indivíduos, o contexto de aplicação da pesquisa, às atividades executadas e aos resultados obtidos no presente artigo, podemos concluir que o ensino tradicional pode trazer consequências na formação dos estudantes no que diz respeito às concepções relativas aos eixos de CTS. A tendência predominante às concepções um (mais de $60 \%$ das respostas) pode ser facilmente entendida como um reflexo desse modelo de ensino que separa os conceitos de Ciência, Tecnologia e Sociedade, ignorando a correlação existente entre eles. A proposta do ensino tradicional de ciências traz a ciência como único foco, sendo ela uma divindade infalível, neutra, apolítica e, conforme previsto na contextualização teórica, essa proposta induz à formação das concepções um de tecnologia e sociedade. Analisando a alta incidência da concepção um de sociedade (62\% das respostas), podemos observar, além da precisão da previsão teórica, uma construção argumentativa oposta a de uma visão crítica, devido a compreensão do fatalismo da sociedade como sistema rígido

e

imutável.

Outra correlação observada no que diz respeito às concepções de Ciência e Sociedade foram os casos em que não foi possível classificar o eixo sociedade na resposta. Em sua maioria, a concepção de Ciência evocada era a um, levantando em nós a pergunta de qual seria a conexão entre esses dados. Pensando que essa visão de ciência é oriunda do ensino tradicional, não podemos ignorar a proposta de dissociar os conceitos de Ciência, Tecnologia e Sociedade (em especial os dois primeiros do último). Analisando essa metodologia, é razoável pensar que ela também gera uma deslegitimação do discurso social. Isso significa que o ensino tradicional também reforça o pensamento de que, quando o tema é científico, o âmbito social não é importante.

Contrariando as previsões iniciais, obtivemos maior incidência da concepção três de Tecnologia (53\% das respostas foram classificadas como concepção 3, enquanto 34\% como concepção 1), onde essa é vista como a materialização da ciência em sistemas e artefatos. Entretanto, ao analisar especificamente as respostas que evocavam as concepções um de Ciências e três de Tecnologia simultaneamente, notamos que 
existe uma maleabilidade nessa concepção de Tecnologia. Simplificando a definição do referencial teórico, chamamos essa concepção de "ciência aplicada" e não explicitamos qual compreensão de ciência tal concepção se refere, deixando-a passível a modificações. Contudo, somente isso não explica sua ampla adesão por parte dos estudantes. A esse fenômeno atribuímos o potencial corruptivo do ensino tradicional e sua visão de Ciência. Podemos pensar que, se a Ciência é compreendida como uma espécie de divindade e a escola é vista como o seu templo, é plausível ver qualquer tema como um subproduto daquela. Assim sendo, se torna plausível a presença majoritária da concepção três de Tecnologia.

Dentro da estrutura escolar atual, os discentes desenvolvem mecanismos e procedimentos para atender as demandas que Ihes são impostas. Dentro desses mecanismos e procedimentos, as formas de interpretar perguntas e elaborar respostas, que se opõem diretamente à nossa idealização de que todas as respostas fossem enquadradas nas concepções três de Ciência, Tecnologia e Sociedade simultaneamente. Isso ocorre, pois, a forma desenvolvida de interpretar e responder as perguntas não exige análise dos conteúdos relacionados entre si ou dentro da realidade vivida, exigindo apenas a resposta "correta". Entendemos, assim, que as respostas que abrangem as concepções três de ciências e sociedade demandam maior reflexão por parte dos estudantes, além de uma visão mais ampla das dimensões que permeiam a atividade. Atingir essa reflexão e entender que a ciência não é inquestionável vai de encontro com o que é desenvolvido dentro de um modelo tradicional de ensino.

É possível concluir, portanto, que o ensino tradicional não tem auxiliado no enfrentamento de problemas como as "fake news", dado que a maior parte dos estudantes não apresenta olhar crítico, inter-relacionando conceitos de Ciência, Tecnologia e Sociedade, de forma a criar uma visão de realidade mais holística. Devido a esse modelo de ensino, até mesmo a análise da confiabilidade das informações dadas em notícias ordinárias se mostra uma tarefa complexa e que não dá clareza em suas respostas. Frente a esses desafios, o uso de uma abordagem CTS é uma das alternativas concretas para ampliar as compreensões sociais e 
tecnológicas e suas conexões com a ciência. Isso se dá pelos princípios dessa abordagem pedagógica, que trata de um estudo de um recorte da realidade analisando tudo que tange o tema. E ainda, a compreensão desses três eixos e suas interconexões é um fator de extrema importância na formação de um cidadão crítico capaz de analisar informações e enfrentar as "fake news" e seu propósito manipulador.

\section{REFERÊNCIAS}

ALLCOTT, H.; GENTZKOW, M. Social Media and Fake News in the 2016 Election. Journal of Economic Perspectives, 31(2), p. 211-236, 2017.

ANTUNES, M. L.; LOPES, C.; SANCHES, T. Literacia da informação no combate às fake news: desafios e estratégias formativas no ensino superior, julho 2019. Disponível em: https://doi.org/10.31229/osf.io/3sbwa

FONSECA, A. B. Ciência, Tecnologia e desigualdade social no Brasil: contribuições da Sociologia do conhecimento para a educação em Ciências. Revista Electrónica de Enseñanza de las Ciências, 6 (2), p. 364-377, 2007.

GELFERT, A. Fake News: A Definition. Informal Logic, 38 (1), p. 84-117, 2018.

JANKOWSKI, N. W. Researching Fake News: A Selective Examination of Empirical Studies. Javnost-The Public, 25(1-2), p. 248-255, 2018.

MARSHALL, J. P. Disinformation Society, communication and cosmopolitan democracy. Cosmopolitan Civil Societies: An Interdisciplinary Journal, 9 (2), p. 1-24, 2017.

MERGULHÃO, D. R. DA S.; MERGULHÃO JÚNIOR, J. C. O.; ALBUQUERQUE, P. F. Post-truth, fake news e processo eleitoral. Revista de Estudos Eleitorais, 2 (4), p. 76 $87,2017$. 
MÜLLER, F. de M.; SOUZA, M. V. de. Fake News: Um problema midiático multifacetado. International Congress of Knowledge and Innovation -Ciki, 1(1), set. 2018. Disponível em: http://proceeding.ciki.ufsc.br/index.php/ciki/article/view/511

PALACIOS, E. M. G.; GALBARTE, J. C. G.; BAZZO, W. Introdução aos estudos CTS (Ciencia, Tecnología e Sociedade). Organización de Estados Iberoamericanos (OEI), 2005.

SANTOS, W. L. P.; MORTIMER, E. F. Uma análise de pressupostos teóricos da abordagem C-T-S (Ciência - Tecnologia - Sociedade) no contexto da educação brasileira. Ensaio: pesquisa em Educação em Ciências, 2 (2), p. 1-23, 2002.

\section{APÊNDICE - REFERÊNCIAS DE NOTA DE RODAPÉ}

4. A expressão é usada para caracterizar o processo de desligamento do Reino Unido da União Europeia iniciado com um referendo.

5. As reticências representam uma palavra não identificável pelos autores.

Enviado: Agosto, 2020.

Aprovado: Setembro, 2020. 